\title{
Third-order nonlinear optical adjusting behavior in azobenzene metal complexes
}

\author{
Chang Xing ${ }^{1 \dagger}$, Jianxun $\mathrm{Liu}^{1 \dagger}$, Linpo Yang ${ }^{2}$, Zhichao Shao ${ }^{1}$, Wenjuan $\mathrm{Xu}^{1}$, Yujie Zhao ${ }^{1} \mathrm{Kai}^{{ }^{1 *}}$, \\ Yinglin Song ${ }^{2}$ and Hongwei Hou ${ }^{1 *}$
}

\begin{abstract}
The third-order nonlinear optical (NLO) materials with stimuli-responsive properties have received extraordinary attention due to their controllable photophysical properties. In this work, two attractive metal complexes thirdorder NLO switches, which are far superior to congeneric optical switches in terms of their performance conversion, versatility, and fast response, were successfully designed and synthesized. The test of their third-order NLO properties proves that the metal complexes exhibit reverse saturable absorption and self-defocusing refraction. After light irradiation, the third-order NLO behavior turns quickly into selffocusing refraction. The relation between the molecular structures and the third-order NLO properties was investigated via ${ }^{1} \mathrm{H}$ nuclear magnetic resonance and ultravioletvisible absorption. The results show that the metal ions have a significant influence on the NLO behavior and reveal the origin of third-order NLO properties via Z-scan determinations, pump-probe technology, and density functional theory calculations. These metal complexes can be used as third-order NLO switches with excellent fatigue resistance and broaden the application range of third-order NLO materials with adjustable performances.
\end{abstract}

Keywords: third-order nonlinear optical, photo-controllable, reversible, signal inversion, metal complex

\section{INTRODUCTION}

In recent years, along with the development of several optical technologies and optoelectronics, molecules with transformation nonlinear optical (NLO) functions have received extensive attention as optical switches [1-4]. Up to now, the NLO switch development is mainly focused on second-order NLO materials [5-9]. Third-order NLO materials show higher performance due to the presence of multiple optical fields which act simultaneously on the material. This makes the research on third-order NLO switches at the forefront [10-13]. Many organic thirdorder NLO switches with high laser damage thresholds and low dielectric constants have been investigated [1416]. However, their low NLO coefficients, single spatial structure, and common electronic property thresholds greatly limit their application prospects. Introducing metal ions into organic materials is an effective strategy to improve the performance of third-order NLO materials. Such metal complexes show the same advantages of organic molecules, while the central metal ions also effectively influences the electronic properties of the organic molecules, improving the response of the third-order NLO compounds [17-19]. More importantly, metal complexes usually exhibit diverse spatial structures and conjugated modes and can provide a wealth of electronic flow systems to enhance and extend NLO behaviors [2027]. Therefore, metal complexes are excellent candidates to develop third-order NLO switches. However, photo switchable third-order NLO complexes remain largely unexplored. Only a few examples have been reported, which still present several disadvantages in terms of performance translation, sensitivity, and response speed [28-31]. In order to obtain ideal photo-controllable thirdorder NLO complexes, one of the most effective strategies is to select suitable organic ligands. These ligands should possess the same characteristics of a large conjugated system, such as a variable structure and a facile coordination with the metal ions. Moreover, they should exhibit third-order NLO properties and an optical switching function. Unfortunately, the majority of the conventional organic ligands, which present an optical response performance, do not possess these properties,

\footnotetext{
${ }^{1}$ Department of Chemistry, Zhengzhou University, Zhengzhou 450001, China

${ }^{2}$ Department of Applied Physics, Harbin Institute of Technology University, Harbin 150001, China

$\dagger$ These authors contributed equally to this work.

* Corresponding authors (emails: houhongw@zzu.edu.cn (Hou H); likai@zzu.edu.cn (Li K))
} 
whereas ligands with a third-order NLO behavior exhibit no optical switching performance [32,33]. The azobenzene molecule shows a significant application prospect in the optical switching field due to its good fatigue resistance and outstanding light response performance $[34,35]$. Moreover, it can undergo cis-trans isomerism under ultraviolet (UV) irradiation [36,37]. Its degree of molecular conjugation changes during the photoisomerization process, leading to the conversion of thirdorder NLO behavior [24,38]. The coupling of azobenzene with metal ions into a new molecular system provides a brand new direction for the design of third-order NLO optical switches.

Based on these considerations, an azobenzene derivative ((E)-5-(((2-methyl-4-(o-tolyldiazenyl)phenyl)amino)methyl)-isophthalic acid $\left(\mathbf{H}_{2} \mathbf{L}\right)$, Scheme 1) with several coordination groups was selected as a ligand to obtain a series of metal complexes. The $\left\{\left[\mathrm{Zn}_{2}(\mathrm{~L})_{2}\left(\mathrm{H}_{2} \mathrm{O}\right)_{4}\right] \cdot 2 \mathrm{DMA}\right.$. $\left.2 \mathrm{H}_{2} \mathrm{O}\right\} \quad(\mathrm{DMA}=\mathrm{N}, \mathrm{N}$-dimethylacetamide $) \quad$ (1) and $\left\{\left[\mathrm{Cd}(\mathrm{L})\left(\mathrm{H}_{2} \mathrm{O}\right)_{3}\right] \cdot \mathrm{DMF} \cdot \mathrm{H}_{2} \mathrm{O}\right\}_{n} \quad$ (2) $\quad(\mathrm{DMF}=\mathrm{N}, \mathrm{N}$-dimethylformamide) complexes with a $D-\pi-D(D=$ donor; $\pi=\pi$ conjugation system) structure were successfully synthesized to test their third-order NLO properties. The $Z$-scan results show that the third-order NLO performance of the complexes is highly enhanced when compared with the $\mathbf{H}_{2} \mathrm{~L}$ ligand. Both $\mathbf{1}$ and $\mathbf{2}$ exhibit the reverse saturable absorption (RSA) and the self-defocusing behaviors. Their third-order NLO performance changes significantly after illumination. The RSA and self-defocusing behaviors disappear rapidly while the self-focusing effects appear. These efficient multi-functional switching behaviors exhibit a good reversibility and fatigue resistance. The mechanistic study of these systems reveals that their molecular structure changes and their effective charge transfer are essential parts to obtain photo-controllable third-order NLO switches. The absorption behavior is believed to be induced by the two-photon absorption (TPA) and the excited state absorption (ESA) mechanisms. Moreover, their refractive performance derives from the Kerr refraction and the excited state refraction mechanisms.

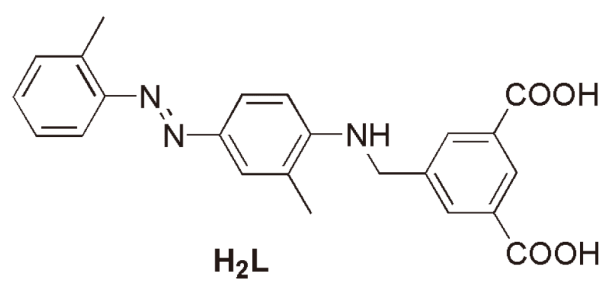

Scheme 1 Chemical structure of $\mathbf{H}_{2} \mathbf{L}$.

\section{EXPERIMENTAL SECTION}

\section{Materials and instruments}

The materials were commercially available and were used without any further purification. 5-Methyl-isophthalic acid, bromobutanimid, and (E)-2-methyl-4-(o-tolyldiazenyl)-aniline hydrochloride metal salts were purchased from J\&K Chemical Co. (Beijing, China). The other materials were purchased from Sinopharm Chemical Reagent Beijing Co. (Beijing, China).

The ${ }^{1} \mathrm{H}$ nuclear magnetic resonance $\left({ }^{1} \mathrm{H}\right.$ NMR) spectra were recorded on a Bruker 600 Avance NMR spectrometer (Germany) operated at $600 \mathrm{MHz}$. The mass spectra were recorded on a Bruker Esquire 3000 plus ion trap mass spectrometer (Brucker-Franzen Analytik GmbH, Germany). A Bruker-ALPHA spectrophotometer was used to perform Fourier transform infrared spectroscopy (FT-IR) with $\mathrm{KBr}$ pellets in the $400-4000 \mathrm{~cm}^{-1}$ range. A series of elemental analyses were carried out on a FLASH EA 1112 analyzer. UV-visible (Vis) absorption spectra in solution were recorded on a JASCO V-750 spectrophotometer by using $4-\mathrm{mL}$ quartz cuvettes $(10 \mathrm{~mm} \times$ $10 \mathrm{~mm}$ ) cells at room temperature. A portable UV Analyzer ZF-5 (400 nm) was used as a light source to induce photo-isomerization. The powder X-ray diffraction (PXRD) patterns were recorded via a PAN alytical X'Pert PRO diffractometer $(\mathrm{Cu} \mathrm{Ka})$. The thermogravimetric analyses (TGA) were carried out by using a Netzsch STA 449 C thermal analyzer (Germany) at a heating rate of $10^{\circ} \mathrm{C} \mathrm{min}^{-1}$ at room temperature.

\section{Syntheses of the ligand and metal complexes}

\section{(E)-5-[(2-Methyl-4-o-tolylazo-phenylamino)-methyl] $\left(\mathrm{Me}_{2} \mathrm{~L}\right)$}

(E)-2-aminoazotoluene $(220 \mathrm{mg}, 0.1 \mathrm{mmol})$, dimethyl-5(bromomethyl) isophthalate $(840 \mathrm{mg}, 0.3 \mathrm{mmol})$, and anhydrous potassium carbonate $(414 \mathrm{mg}, 0.3 \mathrm{mmol}$ ) were added to an acetonitrile solution $(15 \mathrm{~mL})$. The resulting mixture was refluxed for $72 \mathrm{~h}$ and then cooled down to room temperature. The solution was evaporated under a reduced pressure to obtain the crude product, which was purified via column chromatography on silica gel (eluted with $60 \%-80 \%$ ethyl acetate in petroleum ether) to obtain an orange powder. This compound was obtained by evaporating the solution under a reduced pressure of the eluent (yield 70\%). ${ }^{1} \mathrm{H}$ NMR $(600 \mathrm{MHz}$, dimethyl sulfoxide- $\left.d_{6}\left(\mathrm{DMSO}-d_{6}\right), \delta\right) 8.37(\mathrm{~s}, 1 \mathrm{H}, \mathrm{Ar} \mathrm{H}), 8.25$ (s, $2 \mathrm{H}$, $\operatorname{Ar~H}), 7.63$ (s, 1H, Ar H), 7.54 (d, J=8.6 Hz, 1H, Ar H), $7.45(\mathrm{~d}, J=8.0 \mathrm{~Hz}, 1 \mathrm{H}, \mathrm{Ar} \mathrm{H}), 7.33(\mathrm{t}, J=7.7 \mathrm{~Hz}, 1 \mathrm{H}, \mathrm{Ar} \mathrm{H})$, 
$7.30(\mathrm{t}, J=7.2 \mathrm{~Hz}, 1 \mathrm{H}, \mathrm{Ar} \mathrm{H}), 7.24(\mathrm{t}, J=7.5 \mathrm{~Hz}, 1 \mathrm{H}, \mathrm{Ar} \mathrm{H})$, $6.75(\mathrm{t}, J=5.7 \mathrm{~Hz}, 1 \mathrm{H} ; \mathrm{NH}), 6.52(\mathrm{~d}, J=8.7 \mathrm{~Hz}, 1 \mathrm{H}, \mathrm{Ar} \mathrm{H})$, $4.64\left(\mathrm{~d}, J=5.6 \mathrm{~Hz}, 2 \mathrm{H} ; \mathrm{CH}_{2}\right), 3.88\left(\mathrm{~s}, 6 \mathrm{H} ; \mathrm{CH}_{3}\right), 2.59(\mathrm{~s}$, $\left.3 \mathrm{H} ; \mathrm{CH}_{3}\right), 2.30\left(\mathrm{~s}, 3 \mathrm{H} ; \mathrm{CH}_{3}\right)$ (Fig. $\mathrm{S} 1$ ); ${ }^{13} \mathrm{C} \mathrm{NMR}$ $\left(151 \mathrm{MHz}, \mathrm{CDCl}_{3}, \delta\right): 166.10(\mathrm{C}=\mathrm{O}), 151.19(\mathrm{C} 3), 148.06$ (C3), 145.32 (C3), 140.07 (C3), 136.87 (C2), 132.57 (C3), 131.25 (C2), 130.99 (C3), 129.92 (C2), 129.52 (C2), 126.35 (C2), 124.51 (C2), 124.36 (C2), 122.23 (C3), 115.45 (C2), 109.53 (C2), 52.48 (C-O), 47.50 (C2), 17.63 (C1), 17.54 (C1) (Fig. S2); electrospray ionization mass spectrometry (ESI-MS) $m / z(\%):[\mathrm{M}+\mathrm{H}]^{+}$calcd for $\mathrm{C}_{25} \mathrm{H}_{26} \mathrm{~N}_{3} \mathrm{O}_{4}, 432.2$; found: 432.2. Anal. Calcd for $\mathrm{C}_{25} \mathrm{H}_{25} \mathrm{~N}_{3} \mathrm{O}_{4}: \mathrm{C} 69.59, \mathrm{H}$ 5.84, N 9.74; found: C 69.54, H 5.86, N 9.75 (Fig. S3).

\section{(E)-5-(((2-methyl-4-(o-tolyldiazenyl)phenyl)amino)met-} hyl)-isophthalic acid $\left(\boldsymbol{H}_{2} \mathbf{L}\right)$

$\mathbf{M e}_{2} \mathbf{L}$ (430 $\mathrm{mg}, 1.0 \mathrm{mmol}$ ) was dissolved in a mixture of $20 \mathrm{~mL}$ tetrahydrofuran (THF) and $5 \mathrm{~mL} \mathrm{H}_{2} \mathrm{O}$. Then, $\mathrm{NaOH}(80 \mathrm{mg}, 2.0 \mathrm{mmol}$ ) was added. The mixture was stirred and refluxed for $48 \mathrm{~h}$. The solvent was then concentrated by reducing the pressure. The $\mathrm{pH}$ of the concentrated mixture was adjusted to $1-2$ by adding concentrated hydrochloric acid. After stirring for $2 \mathrm{~min}$, an orange precipitate formed, which is the final product of $\mathbf{H}_{2} \mathbf{L}$ ( Scheme S1) (yield: $\left.90 \%\right)$. ${ }^{1} \mathrm{H}$ NMR (600 MHz, DMSO- $\left.d_{6}, \delta\right): 8.36(\mathrm{~s}, 1 \mathrm{H}, \mathrm{Ar} \mathrm{H}), 8.19$ (s, $\left.2 \mathrm{H}, \mathrm{Ar} \mathrm{H}\right), 7.64$ (s, $1 \mathrm{H}, \operatorname{Ar~H}), 7.56(\mathrm{~d}, J=8.5 \mathrm{~Hz}, 1 \mathrm{H}, \operatorname{Ar~H}), 7.46(\mathrm{~d}, J=$ $7.9 \mathrm{~Hz}, 1 \mathrm{H}, \mathrm{Ar} \mathrm{H}), 7.31$ (dt, J=30.9 Hz, $11.9 \mathrm{~Hz}, 2 \mathrm{H}, \mathrm{Ar}$ $\mathrm{H}), 7.24(\mathrm{t}, J=7.4 \mathrm{~Hz}, 1 \mathrm{H}, \mathrm{Ar} \mathrm{H}), 6.74(\mathrm{~s}, 1 \mathrm{H}, \mathrm{NH}), 6.52(\mathrm{~d}$, $J=8.7 \mathrm{~Hz}, 1 \mathrm{H}, \mathrm{Ar} \mathrm{H}), 4.63\left(\mathrm{~d}, J=5.4 \mathrm{~Hz}, 2 \mathrm{H}, \mathrm{CH}_{2}\right), 2.60(\mathrm{~s}$, $\left.3 \mathrm{H}, \mathrm{CH}_{3}\right), 2.30\left(\mathrm{~s}, 3 \mathrm{H}, \mathrm{CH}_{3}\right)$ (Fig. $\left.\mathrm{S} 4\right) ;{ }^{13} \mathrm{C} \mathrm{NMR}$ $\left(151 \mathrm{MHz}, \mathrm{CDCl}_{3}, \delta\right): 167.09(\mathrm{C}=\mathrm{O}), 150.86$ (C3), 149.68 (C3), 144.04 (C3), 141.85 (C3), 136.48 (C2), 132.30 (C3), 131.88 (C2), 131.53 (C3), 129.83 (C2), 129.08 (C2), 126.85 (C2), 124.88 (C2), 124.36 (C2), 122.83 (C3), 115.42 (C2), 109.65 (C2), 46.03 (C2), 18.36 (C1), 17.61 (C1) (Fig. S5); ESI-MS m/z (\%): $[\mathrm{M}+\mathrm{H}]^{+}$calcd for $\mathrm{C}_{23} \mathrm{H}_{22} \mathrm{~N}_{3} \mathrm{O}_{4}, 404.2$; found: 404.2. Calcd for $\mathrm{C}_{23} \mathrm{H}_{21} \mathrm{~N}_{3} \mathrm{O}_{4}$ : C 68.47, $\mathrm{H} 5.25, \mathrm{~N}$ 10.42; found: C 68.45, H 5.23, N 10.41 (Fig. S6).

\section{$\left\{\left[\mathrm{Zn}_{2}(\mathrm{~L})_{2}\left(\mathrm{H}_{2} \mathrm{O}\right)_{4}\right] \cdot 2 \mathrm{DMA} \cdot 2 \mathrm{H}_{2} \mathrm{O}\right\}(\mathbf{1})$}

Both $\mathrm{H}_{2} \mathrm{~L}(0.01 \mathrm{mmol}, 0.004 \mathrm{~g})$ and $\mathrm{Zn}\left(\mathrm{NO}_{3}\right)_{2} \cdot 6 \mathrm{H}_{2} \mathrm{O}$ $(0.02 \mathrm{mmol}, 0.006 \mathrm{~g})$ were dissolved in $\mathrm{DMA} / \mathrm{H}_{2} \mathrm{O}(5 \mathrm{~mL}$, $v / v=2: 3)$ in a glass bottle $(10 \mathrm{~mL})$. The mixture was sealed and heated at $373 \mathrm{~K}$ for 3 days. The solution was then left evaporating and cooling down to room temperature naturally and kept for 7 days. Finally, orange strip crystals appeared. They were separated by filtration and dried in air. Yield: $50 \%$ (based on $\mathrm{Zn}$ ) Anal. Calcd for $\mathrm{C}_{54} \mathrm{H}_{68} \mathrm{~N}_{8} \mathrm{O}_{16} \mathrm{Zn}_{2}$. Calcd (\%): C 53.34, N 9.21, H 5.59; found: C 53.17, N 9.15, H 5.61. IR $\left(\mathrm{KBr}, \mathrm{cm}^{-1}\right)$ : 3422(s), 3019(s), 1606(s), 1578(s), 1519(s), 1416(s), 1368(s), 1329 (s), 1300(s), 1278(s), 1249(m), 1234(s), 1214(m), 1183(m), 1132(m), 1102(m), 1036(w), 1018(w), 995(w), 948(w), 889 $(\mathrm{w}), 812(\mathrm{~m}), 776(\mathrm{~s}), 930(\mathrm{w}), 605(\mathrm{w}), 589(\mathrm{w}), 515(\mathrm{w}), 475$ (w), 456(w) (Fig. S7a).

\section{$\left\{\left[\mathrm{Cd}(\mathrm{L})\left(\mathrm{H}_{2} \mathrm{O}\right)_{3}\right] \cdot \mathrm{DMF} \cdot \mathrm{H}_{2} \mathrm{O}\right\}_{n}(2)$}

Both $\mathbf{H}_{2} \mathbf{L}(0.02 \mathrm{mmol}, 0.008 \mathrm{~g})$ and $\mathrm{Cd}\left(\mathrm{NO}_{3}\right)_{2} \cdot 4 \mathrm{H}_{2} \mathrm{O}$ $(0.05 \mathrm{mmol}, 0.0154 \mathrm{~g})$ were dissolved in $\mathrm{DMF} / \mathrm{H}_{2} \mathrm{O}$ $(3 \mathrm{~mL}, v / v=1: 2)$ in a glass bottle $(10 \mathrm{~mL})$. The mixture was sealed and heated at $373 \mathrm{~K}$ for 3 days. The solution was then left cooling down to room temperature naturally. Finally, orange block crystals appeared. They were separated by filtration and dried in air. Yield: 75\% (based on Cd) Anal. Calcd for $\mathrm{C}_{26} \mathrm{H}_{34} \mathrm{~N}_{4} \mathrm{O}_{9}$ C. Calcd (\%) C 47.39, N 8.50, H 5.20; found: C 47.37, N 8.46, H 5.14. IR (KBr, $\left.\mathrm{cm}^{-1}\right)$ : 3394(s), 2926(m), 1655(s), 1601(s), 1533(s), 1443 (s), 1381(m), 1294(m), 1277(m), 1215(m), 1183(m), 1133 (m), 1103(s), 1037(w), 995(w), 948(w), 893(w), 807(m), 776(w), 730(m), 664(w), 589(w), 458(w) (Fig. S7b).

\section{Single crystal X-ray crystallography}

The crystal data of the compounds $\mathbf{1}$ and $\mathbf{2}$ were collected by using a Bruker D8 VENTURE diffractometer with Mo Ka radiation $(\lambda=0.71073 \AA)$ at $293 \mathrm{~K}$. The SAINT program was employed to integrate the diffraction data, correct the intensity of Lorentz and polarization effects [39]. A semiempirical absorption correction was added by using the SADABS program [40]. The structure was solved by direct ways and refined by employing a full matrix least-squares technique relying on the $F^{2}$ of the SHELXL-2014 software package [41]. The hydrogen atoms were generated geometrically and refined isotropically using the riding model. The crystallographic data and the details about the structure refinement of the complexes $\mathbf{1}$ and $\mathbf{2}$ are shown in Tables S1 and S2.

\section{$Z$-scan technique and pump-probe experiments}

The standard picosecond $Z$-scan technique (ps) and the time-resolved pump-probe with the phase object (POpump-probe) technique (ps) were used to evaluate the third-order NLO properties of the compounds. The experiments were carried out on a TNLO-TR transient nonlinear refractometer (Suzhou Micronano Laser Photon Technology Co., Ltd). A Q-switched Nd:YAG $532 \mathrm{~nm}$ laser (GKPPL-1064-1-10, Beijing GK Laser Technology Co., Ltd.) was used as the light source. The laser provided linearly polarized pulses of $21 \mathrm{ps}$ with a repetition rate of $10 \mathrm{~Hz}$ at $532 \mathrm{~nm}$. In order to ensure the accuracy of the 
experimental data, a quartz glass plate with a solution of CuPcTs/DMSO $\left(2.8 \times 10^{-4} \mathrm{~mol} \mathrm{~L}^{-1}\right)$ was used as a standard sample in the $Z$-scan and time-resolved PO-pump-probe experiments.

\section{RESULTS AND DISCUSSION}

\section{Crystal structure of 1}

The single-crystal XRD measurements demonstrate that $\mathbf{1}$ is a binuclear complex, which belongs to a $P-1$ space group triclinic system. Fig. 1a shows that each elementary unit contains two $\mathrm{Zn}(\mathrm{II})$ ions, two independent transligands, and four coordinated water molecules. Each $\mathrm{Zn}$ (II) ion is penta-coordinated in a distorted trigonal bipyramidal configuration. Moreover, it is surrounded by three $\mathrm{O}$ atoms $(\mathrm{O} 2, \mathrm{O} 3, \mathrm{O} 4)$ belonging to two $\mathrm{L}^{2-}$ ligands, with a $\mathrm{Zn}-\mathrm{O}$ bond length of 1.959(51)-2.489(81) $\AA$, and two $\mathrm{O}$ atoms deriving from the coordinated $\mathrm{H}_{2} \mathrm{O}(\mathrm{O} 5$, O6) with a Zn-O bond length of 1.953(11)-1.964(21) A. The bond angle around $\mathrm{Zn} 1$ varies in the range of 57.255 $(65)^{\circ}-105.898(68)^{\circ}$. In addition, each 1 unit is further linked to an adjacent one to form an overall 1D supramolecule via the $\pi-\pi$ stacking between two benzene rings with a separation of $3.820 \AA$ between the units (Fig. 1b).

\section{Crystal structure of 2}

The single-crystal XRD results reveal that the complex 2 belongs to a $P 21 / c$ space group monoclinic system, which exhibits a 1D linear chain structure. As shown in Fig. 2a, each elementary unit contains one Cd(II) ion, one independent trans-ligand, and three coordinated water molecules. Upon expansion, these compounds generate a chain-shaped polymeric structure. The geometry around each Cd(II) ion consists of a distorted pentagonal bipyramid with only one types of coordination environments (Fig. 2b). The $\mathrm{Cd}(\mathrm{II})$ ion is surrounded by four $\mathrm{O}$ atoms of the two $\mathrm{L}^{2-}$ ligands $(\mathrm{O} 1, \mathrm{O} 2, \mathrm{O} 3, \mathrm{O} 4)$, with a
Cd-O bond length of 2.390(41)-2.394(21) $\AA$, and three O atoms deriving from the coordinated $\mathrm{H}_{2} \mathrm{O}(\mathrm{O} 5, \mathrm{O} 6, \mathrm{O} 7)$ with a Cd-O bond length of 2.299(22)-2.321(42) $\AA$. The bond angles of $\mathrm{O}-\mathrm{Cd}-\mathrm{O}$ fluctuate in the range of 54.175 $(63)^{\circ}-92.601(64)^{\circ}$. Adjacent 1D chains are further linked together to obtain an overall 2D supramolecular framework (Fig. $2 \mathrm{~b}$ ) via the $\pi-\pi$ stacking between two benzene rings separated by $3.766 \AA$ from the adjacent 1D ribbons. One DMF molecule was removed by using the SQUEEZE routine in PLATON. TGA was carried out to verify the molecular structure (Fig. S8). The first mass loss of $11 \%$ takes place in the temperature range of $100-122^{\circ} \mathrm{C}$. It can be attributed to the release of one guest $\mathrm{H}_{2} \mathrm{O}$ molecule and three coordinated water molecules (calcd 10.94\%). The second mass loss of $11.13 \%$ can be attributed to the release of a DMF molecule (calcd 11.09\%) in the temperature range of $122-330^{\circ} \mathrm{C}$. The overall framework of structure 2 starts collapsing at $372.5^{\circ} \mathrm{C}$, which corresponds to the decomposition of $\mathrm{L}^{2-}$. The measured mass reveals the formation of $\mathrm{CdO}$. The final molecular formula of $\mathrm{C}_{26} \mathrm{H}_{34} \mathrm{~N}_{4} \mathrm{O}_{9} \mathrm{Cd}$ was determined by combining the results on the single-crystal structure with the TGA and the elemental analyses.

\section{Third-order NLO switching properties of the metal complexes}

In order to ensure the accuracy of the third-order NLO experimental results, the following exclusion experiments were performed: (I) the UV-Vis absorption spectra (Fig. S9) of the $\mathbf{H}_{2} \mathbf{L}$ and metal complexes were collected in a DMSO solution $\left(4 \times 10^{-5} \mathrm{~mol} \mathrm{~L}^{-1}\right)$; no absorption peak at $532 \mathrm{~nm}$ is visible and this eliminates the possibility of linear absorption. (II) No peak or valley can be observed for pure DMSO in the Z-scan experiment (Fig. S10). This suggests that the third-order NLO behaviors derive only from the solute rather than the solvent. (III) By comparing the ${ }^{1} \mathrm{H}$ NMR spectra of the $\mathbf{H}_{2} \mathbf{L}$ and metal com-
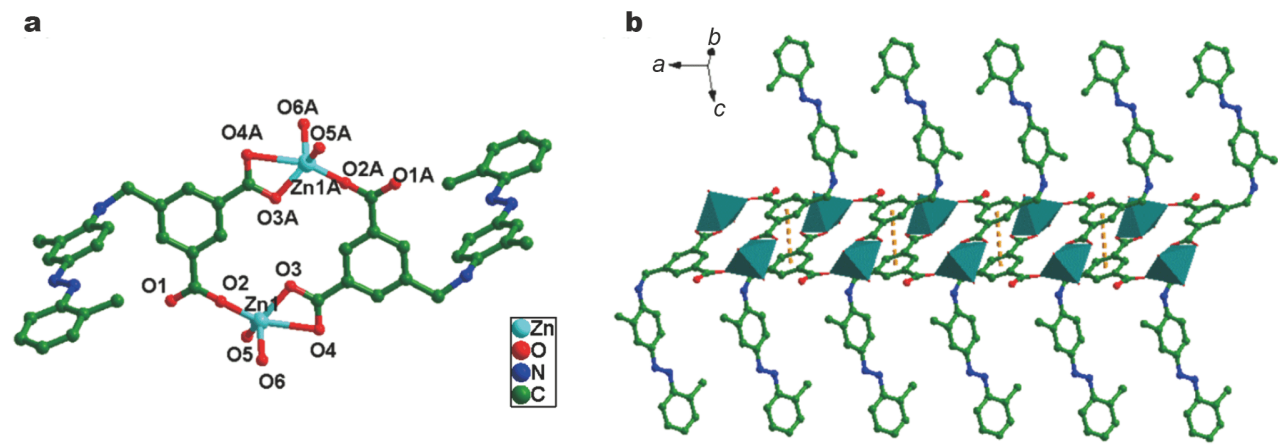

Figure 1 (a) Binuclear framework diagram of 1. (b) Crystal structure diagram of the $\pi-\pi$ accumulation. 
a

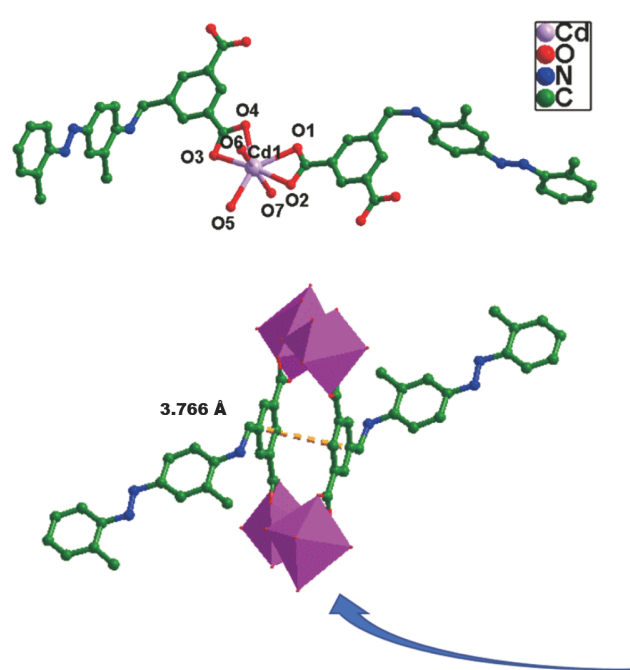

b

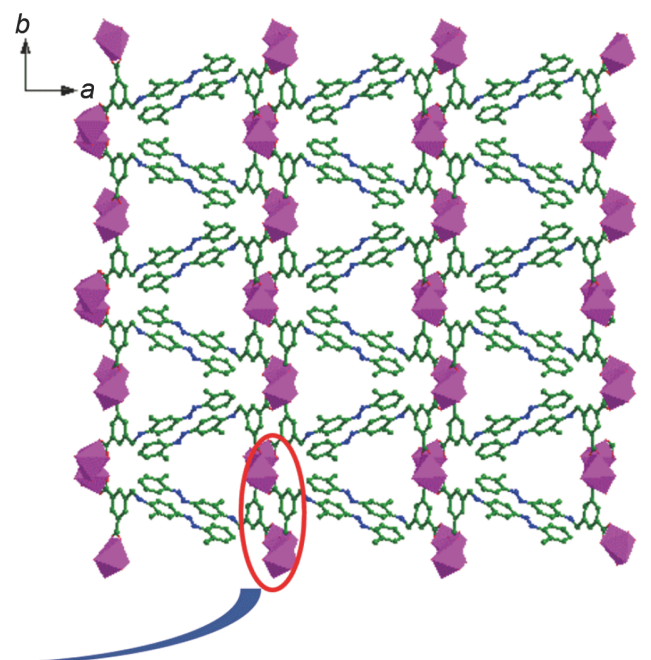

Figure 2 (a) View of coordination environment of Cd (II). (b) $\pi-\pi$ stacking of the $2 \mathrm{D}$ framework.

plexes, the integral areas in the spectra of $\mathbf{H}_{2} \mathbf{L}$ and the metal complex were considered equal. However, the chemical shift of several hydrogen atoms around the isophthalic varies significantly (Figs S11 and S12). These results show that the complexes $\mathbf{1}$ and $\mathbf{2}$ are stable in DMSO solution. (IV) The purity of the compounds $\mathbf{1}$ and 2 were confirmed by the good match of the PXRD patterns and the complex samples (Fig. S13).

The absorption spectra of the complexes in DMSO before and after irradiation were investigated. Before illumination, the strong $\pi-\pi^{*}$ absorption band attributed to a typical trans-azobenzene derivative appears at around $410 \mathrm{~nm}$ (Fig. 3a, b). Upon irradiation at $\lambda=400 \mathrm{~nm}$ for $3 \mathrm{~s}$, the $\pi-\pi^{*}$ absorption band of the trans-isomer significantly decreases. Moreover, a $\pi-\pi^{*}$ transition absorption band appears at $370 \mathrm{~nm}$, as well as a forbidden $n-\pi^{*}$ band at $430 \mathrm{~nm}$, implying the formation of cis-azobenzene $[42,43]$. Two isobestic points become visible, demonstrating that complexes $\mathbf{1}$ and $\mathbf{2}$ undergo photoisomerization from $\boldsymbol{E}$-isomer to $\boldsymbol{Z}$-isomer [44-47]. Fig. $3 \mathrm{c}$, d show an opposite experimental phenomenon, indicating that the cis-isomer transform into a transisomer. Furthermore, the photo-isomerization of the complexes exhibits an excellent fatigue resistance and a high sensitivity, even after 100 cycles of cis $\leftrightarrow$ trans isomerization (Fig. S14).

In order to further confirm the reversible photoisomerization phenomenon in the metal complexes, ${ }^{1} \mathrm{H}$ NMR spectroscopy was used to monitor the progress during the photoisomerization. As a consequence of the distinction between trans- and cis-isomers, the ${ }^{1} \mathrm{H}$ NMR peaks are expected to show subtle differences in the chemical shifts of the aromatic protons. As shown in Fig. 4 and taking 1 as an example, after UV irradiation for $30 \mathrm{~min}$, new features $(7.96,7.06,6.81,6.48,6.20$ and $4.41 \mathrm{ppm})$ can be observed in the ${ }^{1} \mathrm{H}$ NMR spectra. Moreover, the pattern classification of several peaks shows significant changes, such as the transition from $s$ (singlet) classification to $\mathrm{m}$ (multiplet) classification at around $8.43 \mathrm{ppm}$, and from ddd (doublet of doublet of doublets) classification to $\mathrm{m}$ classification at about $7.26 \mathrm{ppm}$, which are attributed to the cis-isomer. The signals belonging to the trans-1 could not disappear completely probably due to the higher concentration (about $0.03 \mathrm{~mol} \mathrm{~L}^{-1}$ ) of the complexes tested for ${ }^{1} \mathrm{H}$ NMR spectra. This concentration is, in fact, much higher than that used for the absorption spectra, leading to a limited transformation rate. When the light is removed, the signals belonging to cis-1 disappear gradually, whereas the ones belonging to trans-1 remain present. This phenomenon proves that the structure $\mathbf{1}$ has underwent a reversible photo-isomerization process. An identical experiment was performed on structure 2 (Fig. S15). These results fully prove that the complexes can be used as photo-controllable materials with a good reversibility.

One can speculate that the occurrence of the photoisomerization behavior may be accompanied by a transformation of the NLO performance. Therefore, the thirdorder NLO absorption and the refractive properties of metal complexes were investigated by performing a series 

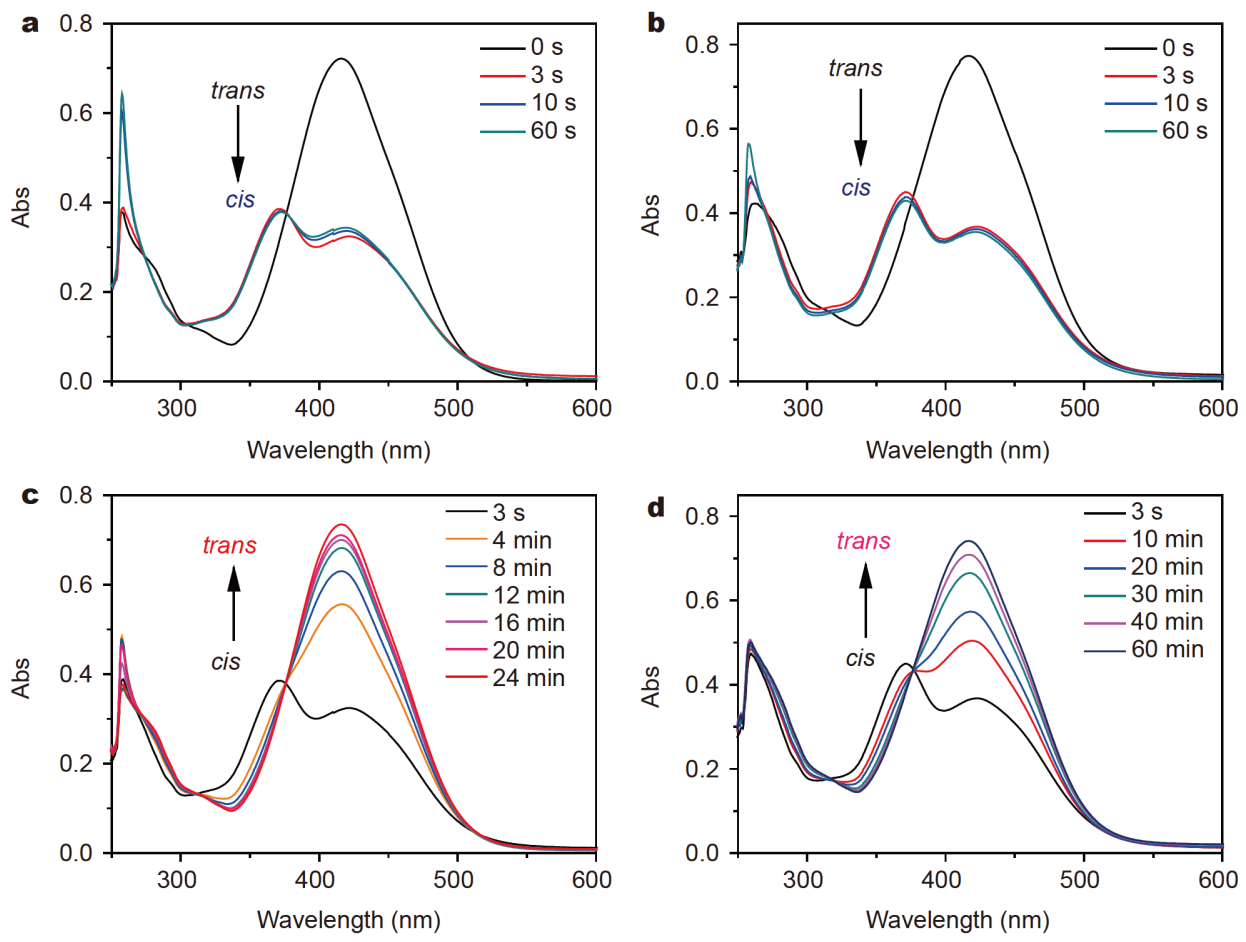

Figure 3 UV-Vis absorption spectra (a, b) upon irradiation and (c, d) in a dark environment. (a, c) For 1; (b, d) for 2. The concentrations of metal complexes are $4 \times 10^{-5} \mathrm{~mol} \mathrm{~L}^{-1}$ in DMSO solution.

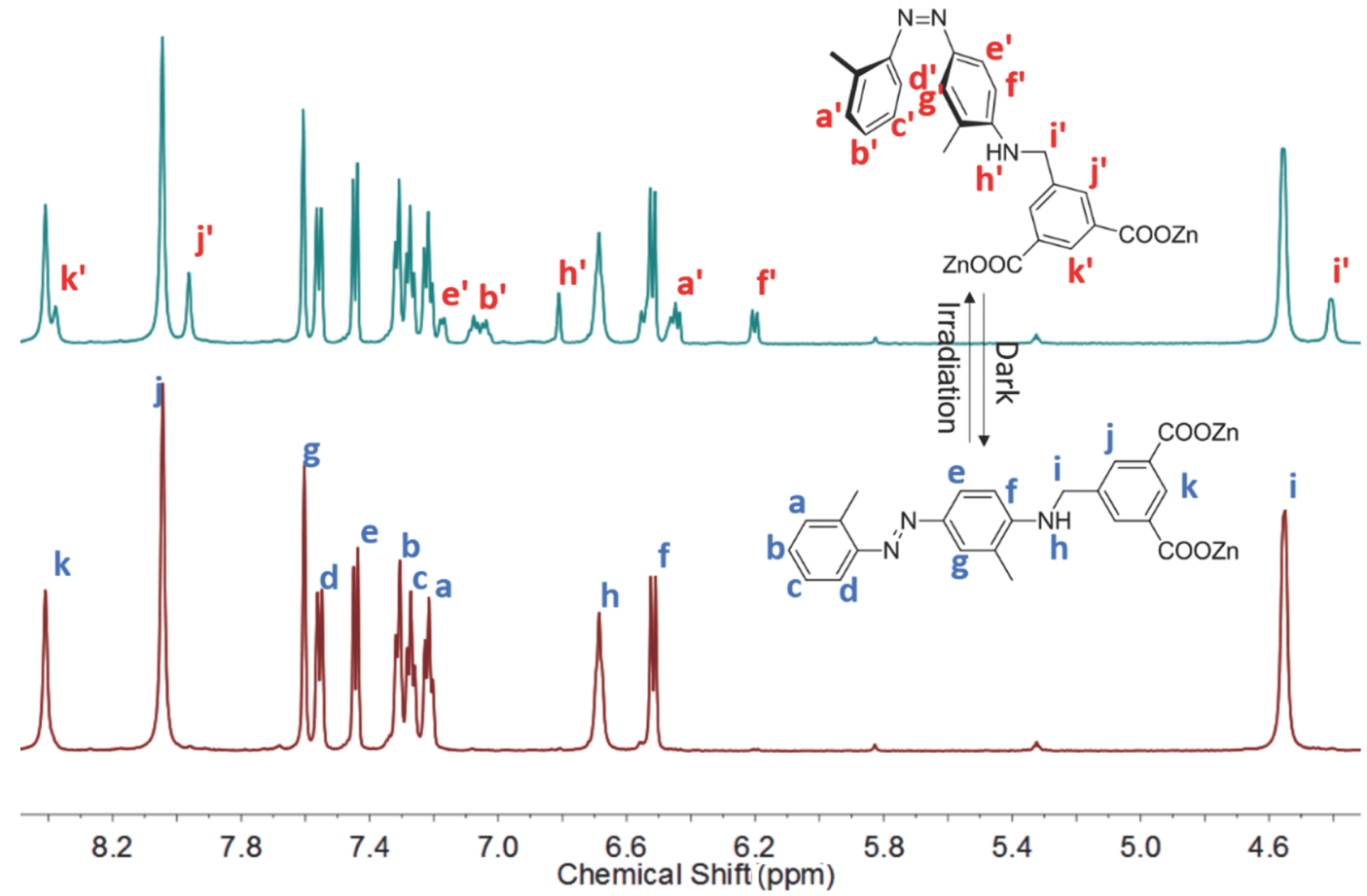

Figure 4 A portion of the ${ }^{1} \mathrm{H}$ NMR spectra of 1 in DMSO- $d_{6}$ under different conditions. 
of Z-scan experiments with open-aperture $(\mathrm{OA})$ and closed-aperture (CA) conditions. The results are shown in Fig. $5 \mathrm{a}, \mathrm{b}$. The normalized transmittance curve presents a minimum in the focal point $(Z=0)$ and the shape of the curve is symmetrical with respect to this point, implying that the two complexes exhibit an RSA performance. Moreover, the experimental data are in good agreement with the theoretical curves. The effective third-order NLO absorptive coefficients $(\beta)$ were calculated to be 5.6 $\times 10^{-12} \mathrm{~m} \mathrm{~W}^{-1}$ for 1 and $3.0 \times 10^{-12} \mathrm{~m} \mathrm{~W}^{-1}$ for 2 (Table S3) $[48,49]$. In addition, the results of the $Z$-scan experiment indicate that the two complexes exhibit strong NLO refractive effects under CA conditions. The spectra show a peak followed by a valley, which occur at equal distances from the focal point. This pattern is typical for a selfdefocusing behavior (Fig. 5c, d). According to the fit data, the third-order NLO refractive indices $\left(n_{2}\right)$ of $\mathbf{1}$ and $\mathbf{2}$ are $-2.0 \times 10^{-16}$ and $-2.6 \times 10^{-16} \mathrm{~m} \mathrm{~W}^{-1}$, respectively [23,50]. A series of $Z$-scan tests were also performed on the samples after illumination: differences in the third-order NLO properties of the complexes can be noticed upon a 400-nm UV irradiation for $1 \mathrm{~min}$. The RSA behavior disappears completely, and the self-defocusing behavior transforms into a self-focusing behavior (Fig. $5 c$, d). The $n_{2}$ of 1 and 2 are $10^{-16}$ and $1.5 \times 10^{-16} \mathrm{~m} \mathrm{~W}^{-1}$, respectively (Table S3). These results suggest that the third-order NLO properties of the complexes can be efficiently modulated by UV light.

In order to thoroughly understand the effect of the metal ions on the third-order NLO properties, $\mathbf{H}_{2} \mathbf{L}$ was analyzed and used as a comparison. By comparing its UV-Vis absorption spectra before and after irradiation (Fig. S16), we find that $\mathbf{H}_{2} \mathbf{L}$ does not undergo a cis-trans conversion. In addition, the $Z$-scan experimental results show that $\mathbf{H}_{2} \mathrm{~L}$ exhibits a single RSA behavior and its third-order NLO properties are independent of UV light (Fig. S17). These phenomena not only demonstrate that the optical properties of the metal complexes are different from those of $\mathbf{H}_{2} \mathbf{L}$, but also provide the possibility to explore the influence of the metal ions on the NLO properties. The analyses of the NMR and the UV-Vis absorption spectra of the complexes show that the isomerization process induces a transformation in the thirdorder NLO behavior of the materials. Therefore, it is worth exploring the relation between the metal ions and the isomerization behavior of materials. Based on the literature reports [51-55], several azo compounds with special groups do not normally exhibit isomerization. The
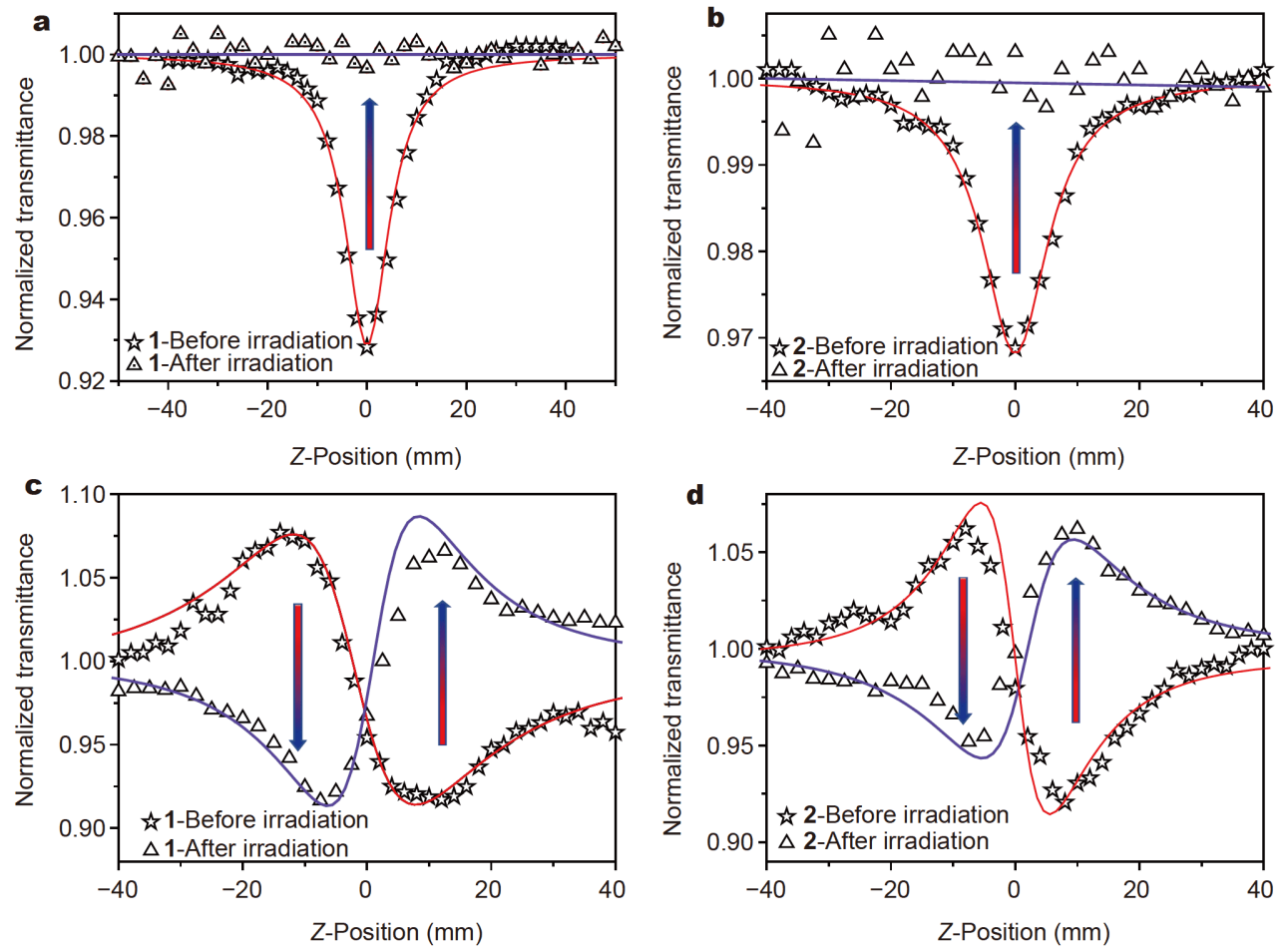

Figure 5 (a, b) Open-aperture and (c, d) closed-aperture $Z$-scan results on the $\mathbf{1}$ and $\mathbf{2}$. The red and blue solid lines correspond to the fitting curves before and after the irradiation, respectively. The concentrations of the metal complexes are $1 \times 10^{-3} \mathrm{~mol} \mathrm{~L}^{-1}$ in DMSO solution. 
carboxyl group belongs to these special classes. The hydrogen ions dissociate from the carboxyl groups and interact with the nitrogen atoms of the azobenzene group to inhibit the trans $\rightarrow$ cis isomerization or to speed up the cis $\rightarrow$ trans isomerization process. When the hydrogen atom of the carboxyl groups in $\mathbf{H}_{2} \mathbf{L}$ is replaced by a metal ion, the optical-response performance of the compound is activated and $\mathbf{H}_{2} \mathbf{L}$ becomes a potential photo-responsive switchable material. This is the reason why 1 and $\mathbf{2}$ exhibit outstanding photo-controllable third-order NLO switching properties contrarily to $\mathbf{H}_{2} \mathbf{L}$.

In order to further explore the influence of the metal ions on the third-order NLO properties, density functional theory (DFT) calculations were carried out at the B3LYP/6-31G (d,p) level after the trans-structures of the compounds were fully optimized with the Gaussian 09 software. The structure of the complexes is nearly symmetrical. This is visible due to the presence of the two sets of degenerate orbitals with subequal energies (Fig. S18). By analyzing the DFT calculation results and the results of the third-order NLO properties for the complexes 1, 2, and $\mathbf{H}_{2} \mathbf{L}$, it can be found that the gaps of the complexes are smaller than that of $\mathbf{H}_{2} \mathbf{L}$. Moreover, the absorption coefficient of the complexes is higher than that of $\mathbf{H}_{2} \mathbf{L}$. These results show that the coordination with the metal ions modifies the strength of the third-order NLO behavior by affecting the energy gap of the molecules.

\section{Study on the third-order NLO mechanism}

There exist many mechanisms that explain the origin of the third-order NLO performances, such as ESA, TPA, and the optical Kerr effects [56,57]. Generally speaking, the nonlinear absorption behavior depends on the ground state absorption cross section $\left(\sigma_{\mathrm{s} 0}\right)$ and the excited state absorption cross section $\left(\sigma_{\mathrm{s} 1}\right)$. When $\sigma_{\mathrm{s} 1}>\sigma_{\mathrm{s} 0}$, the material exhibits RSA properties; whereas it presents a saturable absorption (SA) performance if $\sigma_{\mathrm{s} 1}<\sigma_{\mathrm{s} 0}$. The larger the values of $\sigma_{1} / \sigma_{0}$ and $\beta_{\mathrm{TPA}}$ are, the better NLO properties the material possesses. The nonlinear refraction behavior is determined by refraction index per unit density $\left(\Delta \eta_{\mathrm{s} 1}\right)$ of the material. When $\Delta \eta_{\mathrm{s} 1}>0$, the compound exhibits selffocusing, whereas when $\Delta \eta_{\mathrm{S}_{1}}<0$, the matter exhibits selfdefocusing.

In order to deeply understand the third-order NLO performance of such complexes, a series of ps pumpprobe experiments (Fig. S19) and a five-level model (Fig. S20) were simultaneously used to analyze the $Z$-scan results. Initially, the third-order NLO absorption mechanisms were investigated. The transient absorption spectra of the complexes were obtained under OA con- ditions (Fig. 6a, b). In the negative delay region, the delay time is lower than 0 , whereas the normalized transmittance equals to 1 . The probe beam irradiates the sample earlier than the pump beam, and the probe beam intensity is too weak to trigger the NLO behaviors of the materials. When the delay time is close to zero, the normalized transmittance decreases dramatically at first and then increases gradually. The sharp valleys near the zero-delay time are a characteristic of the TPA process. In the positive delay region, the normalized transmittance does not return to its initial state, which is typical for the ESA process. The experimental results fully demonstrate that the NLO absorption behavior of $\mathbf{1}$ and $\mathbf{2}$ is derived from TPA and ESA $[49,58,59]$. The two absorption mechanisms are described in detail via the five-level model. In the negative delay region, the electrons are in the ground state $\left(\mathrm{S}_{0}\right)$. In the delay region close to zero, the electrons transfer from the $S_{0}$ to the high singlet excited state, $S_{1}$, or to even higher excited states by TPA. Most of the excited electrons relax back to $S_{0}$ quickly via a radiation-free transition. However, a few electrons still remain in the $S_{1}$ state. The pump-probe parameters of the complexes are listed in Table S4. The $\sigma_{\mathrm{s} 1}$ and the $\sigma_{\mathrm{s} 0}$ of $\mathbf{1}$ and 2 are $6.94 \times 10^{-23}, 8.85 \times 10^{-23} \mathrm{~m}^{2}$, and $6.14 \times 10^{-23}, 8.05 \times$ $10^{-23} \mathrm{~m}^{2}$, respectively. Both the complexes show $\sigma_{\mathrm{s} 1}>\sigma_{\mathrm{s} 0}$, implying that the RSA process occurs. Generally, the higher $\sigma_{\mathrm{s} 1} / \sigma_{\mathrm{s} 0}$ and $\beta_{\mathrm{TPA}}$ are, the stronger the NLO absorption behavior is. The $\sigma_{\mathrm{s} 1} / \sigma_{\mathrm{s} 0}$ measures: $1 \mathrm{E}(1.13)>\mathbf{2 E}$ (1.09) (1E and 2E refer to the trans-form of $\mathbf{1}$ and 2, respectively), and $\beta_{\mathrm{TPA}}$ measures: $1 \mathrm{E}\left(5.3 \times 10^{-12} \mathrm{~m} \mathrm{~W}^{-1}\right)$ $>2 \mathrm{E}\left(2.2 \times 10^{-12} \mathrm{~m} \mathrm{~W}^{-1}\right)$. These results fit with the $Z$-scan results where $\beta$ measures of $1 \mathrm{E}\left(5.6 \times 10^{-12} \mathrm{~m} \mathrm{~W}^{-1}\right)>\mathbf{2 E}$ $\left(3.3 \times 10^{-12} \mathrm{~m} \mathrm{~W}^{-1}\right)$. The small value of $\tau_{\mathrm{S} 1}$ implies that the complexes have a fast response, which is an advantage in optical switches. Similarly to the $Z$-scan results, no signal was detected in the pump-probe experiment for $\mathbf{1 Z}$ and $\mathbf{2 Z}(\mathbf{Z Z}$ and $\mathbf{2 Z}$ refer to the cis-form of $\mathbf{1}$ and $\mathbf{2}$, respectively).

The mechanism of third-order NLO refraction was explored via a pump-probe experiment in the CA conditions (Fig. 6c, d). The experimental values are summarized in Table S5. Before illumination, a sharp valley is present near the zero-delay time, and the normalized transmittance in the positive delay region quickly returns to its original state. This shows that the refraction performance of these complexes depends on pure Kerr refraction $\left(\Delta \eta_{s 1}=0\right)$ [50,60-62]. The "sharp valley" for both complexes shows a self-defocusing refraction behavior, which is consistent with the experimental results of the $Z$ scan. After irradiation, a sharp peak appears at a zero- 

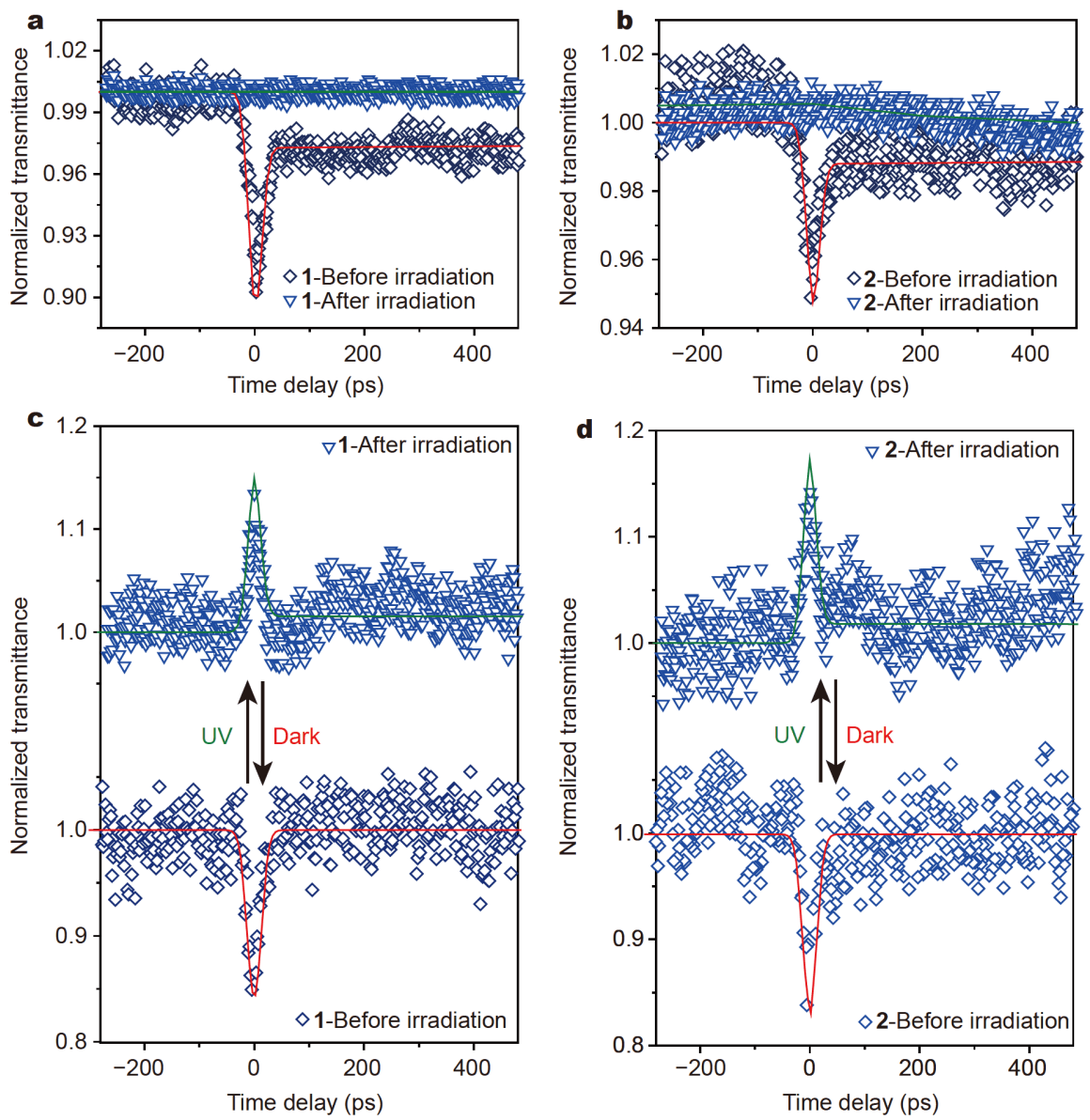

Figure 6 (a, b) OA and (c, d) CA pump-probe results of the metal complexes. The green and red solid lines correspond with the fitting curves. The concentrations of the metal complexes are $3 \times 10^{-3} \mathrm{~mol} \mathrm{~L}^{-1}$ in DMSO solution.

delay time and is characteristic for the Kerr refraction. The normalized transmittance in the positive delay region does not return to the state of the negative delay one. These results demonstrate that the third-order NLO refraction properties after illumination originate from the Kerr refraction and the excited state refraction [63,64]. According to five-level model, the refraction parameters of $1 \mathrm{Z}$ and $\mathbf{2 Z}$ were calculated $\left(1.8 \times 10^{-24} \mathrm{~cm}^{3}\right.$ for $\mathbf{1 Z}, 1 \times$ $10^{-24} \mathrm{~cm}^{3}$ for $2 Z$ ). The magnitude of $\Delta \eta_{\mathrm{s} 1}>0$ implies that the complexes exhibit a self-focusing behavior. The pump-probe experiments not only reveal the origin of the third-order NLO properties, but also verify the accuracy of the $Z$-scan results. Furthermore, DFT calculations were carried out to understand the third-order NLO properties of the complexes. The structure of the complexes is nearly symmetric with two sets of degenerate orbitals. Figs S21 and S22 show that the highest occupied molecular orbital (HOMO) and the HOMO-1 (or the lowest unoccupied molecular orbital (LUMO) and the LUMO+1) are de- generate orbitals with subequal energies. The two benzene rings in the azobenzene group of the trans-isomer are coplanar, implying the presence of intramolecular charge transfer. A certain degree of torsion between the two benzene rings in the azobenzene group of the cis-isomer arises due to steric hindrance. These differences lead to different $\sigma_{\mathrm{s} 0}, \sigma_{\mathrm{s} 1}$, and $\Delta \eta_{\mathrm{s} 1}$ values for the trans and cis structures-these parameters directly affect their properties. The energy gap of $\mathbf{1}$ increases from about $3.38 \mathrm{eV}$ (1E) to $3.44 \mathrm{eV}(\mathbf{1 Z})$, whereas in the energy gap of 2 increases from about $3.34 \mathrm{eV}(\mathbf{2 E})$ to $3.45 \mathrm{eV}(\mathbf{2 Z})$ after irradiation under $400 \mathrm{~nm}$ light. Normally, a higher energy gap does not always generate a larger third-order NLO absorption $[65,66]$. Thus, the trans to cis isomerization may be the main reason behind the disappearance of the RSA signal of $\mathbf{1}$ and $\mathbf{2}$ after irradiation.

\section{CONCLUSIONS}

In summary, two novel third-order NLO photo- 
controlled switches were investigated. They show an excellent reversibility, fatigue resistance, and a fast and complete conversion between different third-order NLO performances. Moreover, the introduction of the metal ions into the organic compound system effectively increases its activity and reduces the energy gap of the molecular structure. This drastically enhances the thirdorder NLO properties of the metal complexes. These interesting findings may be helpful in designing high-performance versatile NLO materials and to expand the application range of the optical switches.

Received 18 April 2020; accepted 12 June 2020;

published online 24 September 2020

1 Biswal BP, Valligatla S, Wang M, et al. Nonlinear optical switching in regioregular porphyrin covalent organic frameworks. Angew Chem Int Ed, 2019, 58: 6896-6900

2 Castet F, Rodriguez V, Pozzo JL, et al. Design and characterization of molecular nonlinear optical switches. Acc Chem Res, 2013, 46: 2656-2665

3 Huang J, Guo S, Zhang Z, et al. Designing excellent mid-infrared nonlinear optical materials with fluorooxo-functional group of $\mathrm{d}^{0}$ transition metal oxyfluorides. Sci China Mater, 2019, 62: 17981806

4 Samoc M, Gauthier N, Cifuentes MP, et al. Electrochemical switching of the cubic nonlinear optical properties of an aryldiethynyl-linked heterobimetallic complex between three distinct states. Angew Chem Int Ed, 2006, 45: 7376-7379

5 Aubert V, Guerchais V, Ishow E, et al. Efficient photoswitching of the nonlinear optical properties of dipolar photochromic zinc(II) complexes. Angew Chem Int Ed, 2008, 47: 577-580

6 Boixel J, Guerchais V, Le Bozec H, et al. Second-order NLO switches from molecules to polymer films based on photochromic cyclometalated platinum(II) complexes. J Am Chem Soc, 2014, 136: $5367-5375$

7 Nitadori H, Ordronneau L, Boixel J, et al. Photoswitching of the second-order nonlinearity of a tetrahedral octupolar multi DTEbased copper(I) complex. Chem Commun, 2012, 48: 10395-10397

8 Shi Z, Qin L, Zheng H. A second-order nonlinear optical material with a 5 -fold interpenetrating diamondoid framework based on two achiral precursors: spontaneous resolution to absolute chiral induction. Dalton Trans, 2017, 46: 4589-4594

9 Xing XS, Sa RJ, Li PX, et al. Second-order nonlinear optical switching with a record-high contrast for a photochromic and thermochromic bistable crystal. Chem Sci, 2017, 8: 7751-7757

10 Barlow S, Brédas JL, Getmanenko YA, et al. Polymethine materials with solid-state third-order optical susceptibilities suitable for alloptical signal-processing applications. Mater Horiz, 2014, 1: 577581

11 Gieseking RLM. Third-order nonlinear optical properties of Ag nanoclusters: Connecting molecule-like and nanoparticle-like behavior. Chem Mater, 2019, 31: 6850-6859

12 Gulino A, Compagnini G, Scalisi AA. Large third-order nonlinear optical properties of cadmium oxide thin films. Chem Mater, 2003, 15: 3332-3336

13 Hales JM, Matichak J, Barlow S, et al. Design of polymethine dyes with large third-order optical nonlinearities and loss figures of merit. Science, 2010, 327: 1485-1488

14 Jia J, Zhang J, Zhou C, et al. Extended $\pi$-conjugated quinazolinone derivatives with enhanced third-order nonlinear optical response. Dyes Pigments, 2019, 166: 314-322

15 Traber B, Wolff JJ, Rominger F, et al. Hexasubstituted donoracceptor benzenes as nonlinear optically active molecules with multiple charge-transfer transitions. Chem Eur J, 2004, 10: 12271238

16 Xing C, Liu J, Chen F, et al. Diphenyl-1-pyrenylphosphine: Phototriggered AIE/ACQ transition with remarkable third-order nonlinear optical signal change. Chem Commun, 2020, 56: 4220-4223

17 Liang X, Zhang Q. Recent progress on intramolecular chargetransfer compounds as photoelectric active materials. Sci China Mater, 2017, 60: 1093-1101

18 Yin W, Tao C, Wang F, et al. Tuning optical properties of MOFbased thin films by changing the ligands of MOFs. Sci China Mater, 2017, 61: 391-400

19 Yue Y, Grusenmeyer T, Ma Z, et al. Full-electron ligand-to-ligand charge transfer in a compact $\operatorname{Re}(\mathrm{I})$ complex. J Phys Chem A, 2014, 118: $10407-10415$

20 Hou H, Wei Y, Song Y, et al. Metal ions play different roles in the third-order nonlinear optical properties of $\mathrm{d}^{10}$ metal-organic clusters. Angew Chem Int Ed, 2005, 44: 6067-6074

21 Kulyk B, Guichaoua D, Ayadi A, et al. Functionalized azo-based iminopyridine rhenium complexes for nonlinear optical performance. Dyes Pigments, 2017, 145: 256-262

22 Wang HY, Jing LX, Wang HQ, et al. Improving the NLO response of bis-cyclometalated iridium(III) complexes by modifying ligands: A DFT study. J Organomet Chem, 2018, 869: 18-25

23 Chen QF, Zhao X, Liu Q, et al. Tungsten(VI)-copper(I)-sulfur cluster-supported metal-organic frameworks bridged by in situ click-formed tetrazolate ligands. Inorg Chem, 2017, 56: 5669-5679

24 Chen X, Li HX, Zhang ZY, et al. Activation and amplification of the third-order NLO and luminescent responses of a precursor cluster by a supramolecular approach. Chem Commun, 2012, 48: 4480

25 Wei ZH, Ni CY, Li HX, et al. $[\mathrm{PyH}]\left[\left\{\operatorname{TpMo}\left(\mu_{3}-\mathrm{S}\right)_{4} \mathrm{Cu}_{3}\right\}_{4}\left(\mu_{12}-\mathrm{I}\right)\right]$ : A unique tetracubane cluster derived from the $\mathrm{S}-\mathrm{S}$ bond cleavage and the iodide template effects and its enhanced NLO performances. Chem Commun, 2013, 49: 4836-4838

26 Zhang WH, Ren ZG, Lang JP. Rational construction of functional molybdenum (tungsten)-copper-sulfur coordination oligomers and polymers from preformed cluster precursors. Chem Soc Rev, 2016, 45: 4995-5019

27 Qiu XT, Yao R, Zhou WF, et al. Rectangle and [2]catenane from cluster modular construction. Chem Commun, 2018, 54: 41684171

28 Chen Z, Dong S, Zhong C, et al. Photoswitching of the third-order nonlinear optical properties of azobenzene-containing phthalocyanines based on reversible host-guest interactions. J Photochem Photobiol A-Chem, 2009, 206: 213-219

29 Feng Q, Li Y, Shi G, et al. A photo-controllable third-order nonlinear optical (NLO) switch based on a rhodamine B salicylaldehyde hydrazone metal complex. J Mater Chem C, 2016, 4: 85528558

30 Ordronneau L, Aubert V, Guerchais V, et al. The first hexadithienylethene-substituted tris(bipyridine)metal complexes as quadratic NLO photoswitches: Combined experimental and DFT studies. Chem Eur J, 2013, 19: 5845-5849

31 Wang HQ, Wang L, Ye JT, et al. Planar octagonal tetranuclear 
cobaltacarborane macrocycle $\left[\left(\eta^{5}-\mathrm{C}_{5} \mathrm{Me}_{5}\right) \mathrm{Co}\left(2,3-\mathrm{Et}_{2} \mathrm{C}_{2} \mathrm{~B}_{4} \mathrm{H}_{3}-5-\right.\right.$ $\mathrm{C} \equiv \mathrm{C}-7-\mathrm{C} \equiv \mathrm{C})]_{4}$ for $2 \mathrm{D}$ nonlinear optics: Ultra-high-response and multistate controlled cubic NLO switch. J Phys Chem C, 2017, 121: 28462-28474

$32 \mathrm{Wu}$ X, Xiao J, Sun R, et al. Spindle-type conjugated compounds containing twistacene unit: Synthesis and ultrafast broadband reverse saturable absorption. Adv Opt Mater, 2017, 5: 1600712

33 Ouyang $\mathrm{H}$, Zhang $\mathrm{C}$, Liu Q, et al. Polarization-tunable nonlinear absorption patterns from saturated absorption to reverse saturated absorption in anisotropic GeS flake and an application of all-optical switching. Sci China Mater, 2020, 63: 1489-1502

34 Cabré G, Garrido-Charles A, Moreno M, et al. Rationally designed azobenzene photoswitches for efficient two-photon neuronal excitation. Nat Commun, 2019, 10: 907

35 Xie Y, Fu D, Jin O, et al. Photoswitchable molecular switches featuring both axial and tetrahedral chirality. J Mater Chem C, 2013, 1: 7346-7356

36 Boelke J, Hecht S. Designing molecular photoswitches for soft materials applications. Adv Opt Mater, 2019, 7: 1900404

37 Probst C, Meichner C, Kreger K, et al. Athermal azobenzene-based nanoimprint lithography. Adv Mater, 2016, 28: 2624-2628

38 Xue X, Wang H, Han Y, et al. Photoswitchable nonlinear optical properties of metal complexes. Dalton Trans, 2018, 47: 13-22

39 SAINT: Program for data extraction and reduction. Madison WI: Bruker AXS Inc., 2001

40 Sheldrick GM. SADABS. Program for empirical adsorption correction of area detector data. Göttingen: University of Gottingen, 2003

41 Sheldrick GM. Crystal structure refinement with SHELXL. Acta Cryst, 2015, C71: 3-8

42 Chen S, Zhang W, Wang C, et al. A recycled foam coloring approach based on the reversible photo-isomerization of an azobenzene cationic surfactant. Green Chem, 2016, 18: 3972-3980

43 Wang H, Bisoyi HK, McConney ME, et al. Visible-light-induced self-organized helical superstructure in orientationally ordered fluids. Adv Mater, 2019, 31: 1902958

44 Cai Y, Gao Y, Luo Q, et al. Ferrocene-grafted photochromic triads based on a sterically hindered ethene bridge: redox-switchable fluorescence and gated photochromism. Adv Opt Mater, 2016, 4: 1410-1416

45 He Y, Li Y, Su H, et al. An o-phthalimide-based multistimuliresponsive aggregation-induced emission (AIE) system. Mater Chem Front, 2019, 3: 50-56

46 McQuade DT, O'Brien AG, Dörr M, et al. Continuous synthesis of pyridocarbazoles and initial photophysical and bioprobe characterization. Chem Sci, 2013, 4: 4067

47 Villar-Acevedo G, Lugo-Mas P, Blakely MN, et al. Metal-assisted oxo atom addition to an $\mathrm{Fe}(\mathrm{III})$ thiolate. J Am Chem Soc, 2017, 139: $119-129$

$48 \mathrm{Xu} \mathrm{W}$, Shao Z, Han Y, et al. Light-adjustable third-order nonlinear absorption properties based on a series of hydrazone compounds. Dyes Pigments, 2018, 152: 171-179

49 Zheng X, Feng M, Li Z, et al. Enhanced nonlinear optical properties of nonzero-bandgap graphene materials in glass matrices. J Mater Chem C, 2014, 2: 4121-4125

50 Fang Y, Xiao Z, Wu X, et al. Optical nonlinearities and ultrafast alloptical switching of $m$-plane GaN in the near-infrared. Appl Phys Lett, 2015, 106: 251903

51 Klotz IM, Fiess HA, Chen Ho JY, et al. The position of the proton in substituted azobenzene molecules. J Am Chem Soc, 1954, 76:
5136-5140

52 Lovrien R, Pesheck P, Tisel W. Protein and hydrogen ion control of photochromism in aminoazobenzene compounds. J Am Chem Soc, 1974, 96: 244-248

53 Nihei M, Kurihara M, Mizutani J, et al. Synthesis of azo-conjugated metalladithiolenes and their photo- and proton-responsive isomerization reactions. J Am Chem Soc, 2003, 125: 2964-2973

54 Wettermark G, Langmuir ME, Anderson DG. Catalysis of the cis $\rightarrow$ trans isomerization of 2-hydroxy-5-methylazobenzene. J Am Chem Soc, 1965, 87: 476-481

55 Zhai $\mathrm{Y}, \mathrm{Xu} \mathrm{W}$, Meng X, et al. Adjusting the third-order nonlinear optical switch performance based on azobenzene derivatives. Acta Chim Sin, 2020, 78: 256-262

56 Ma CR, Xiao J, Yang GW. Giant nonlinear optical responses of carbyne. J Mater Chem C, 2016, 4: 4692-4698

57 Sreekumar G, Louie Frobel PG, Sreeja S, et al. Nonlinear absorption and photoluminescence emission in nanocomposite films of fuchsine basic dye-polymer system. Chem Phys Lett, 2011, 506: 61-65

58 Li L, Shang X, Wang S, et al. Bilayered hybrid perovskite ferroelectric with giant two-photon absorption. J Am Chem Soc, 2018, 140: 6806-6809

59 Russier-Antoine I, Bertorelle F, Calin N, et al. Ligand-core NLOphores: A combined experimental and theoretical approach to the two-photon absorption and two-photon excited emission properties of small-ligated silver nanoclusters. Nanoscale, 2017, 9: 12211228

60 Drori J, Rosenberg Y, Bermudez D, et al. Observation of stimulated hawking radiation in an optical analogue. Phys Rev Lett, 2019, 122: 010404

61 Margulis VA, Muryumin EE, Gaiduk EA. Optical Kerr effect and two-photon absorption in monolayer black phosphorus. J Opt, 2018, 20: 055503

62 Peruch S, Neira A, Wurtz GA, et al. Geometry defines ultrafast hot-carrier dynamics and Kerr nonlinearity in plasmonic metamaterial waveguides and cavities. Adv Opt Mater, 2017, 5: 1700299

63 Meng X, Zhou Y, Chen K, et al. Anisotropic saturable and excitedstate absorption in bulk $\operatorname{ReS}_{2}$. Adv Opt Mater, 2018, 6: 1800137

64 Xie Q, Shao Z, Zhao Y, et al. Novel photo-controllable third-order nonlinear optical (NLO) switches based on azobenzene derivatives. Dyes Pigments, 2019, 170: 107599

65 Jia J, Wu X, Fang Y, et al. Ultrafast broad-band optical limiting in simple hydrazone derivatives with a П-conjugated system: Effect of two-photon-induced singlet-state absorption. J Phys Chem C, 2018, 122: 16234-16241

$66 \mathrm{Xu} \mathrm{W}$, Wang W, Li J, et al. Two-photon absorption property and excellent optical limiting response of three Schiff base derivatives with large conjugated system. Dyes Pigments, 2019, 160: 1-8

Acknowledgements This work was supported by the National Natural Science Foundation of China (21671174 and U1904172), the Zhongyuan Thousand Talents Project, the Natural Science Foundation of Henan Province (182300410008), and the Open Foundation of Guangxi Key Laboratory of Processing for Nonferrous Metals and Featured Materials, Guangxi University (2019GXYSOF12).

Author contributions Xing C and Liu J carried out the experiments and analyzed the date; Hou $\mathrm{H}$ conceived the idea; $\mathrm{Li} \mathrm{K}$ contributed to the improvement of the manuscript; Yang L and Song Y provided technical support; Shao Z, Xu W and Zhao Y contributed to the general discus- 
sion. The final version of the manuscript was approved by all authors.

Conflict of interest The authors declare that they have no conflict of interest.

Supplementary information online version of the paper.

Supporting data are available in the

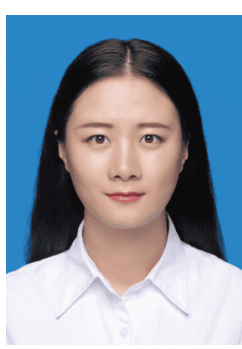

Chang Xing is studying for a master's degree under the supervision of Prof. Hongwei Hou in Zhengzhou University. Her research interest focuses on the synthesis and application of metal complex with third-order nonlinear optical property.

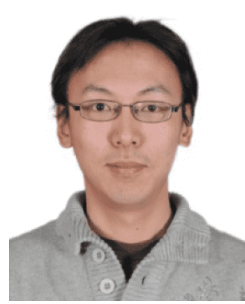

Kai Li obtained his $\mathrm{PhD}$ degree from Tsinghua University in 2014. Now, he is an associate professor at the Department of Chemistry in Zhengzhou University. His research interests mainly focus on the development and application of aggregation-induced emission materials and photo-responsive fluorescent materials.

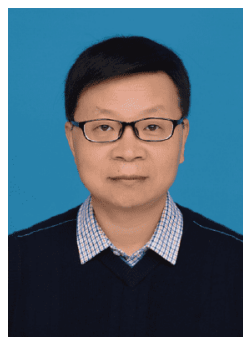

Hongwei Hou received his $\mathrm{PhD}$ degree from Nanjing University in 1995 . He works as a professor at the Department of Chemistry in Zhengzhou University since he returned from Singapore in 1998. His research interests include the syntheses and applications of nonlinear optical materials and crystalline metal-organic framework (MOF) molecular reactors.

\section{具有可调节三阶非线性光学性能的偶氮苯金属配 合物 \\ 邢畅 $^{1 \dagger}$, 刘建勋 ${ }^{1 \dagger}$, 杨林坡 ${ }^{2}$, 邵志超 ${ }^{1}$, 许文娟 ${ }^{1}$, 赵玉洁 ${ }^{1}$, 李惝 ${ }^{*}$,

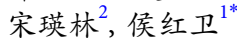

摘要 具有刺激响应性的三阶非线性光学材料由于其可控的光物 理性质而受到了广泛的关注. 本文设计并合成了两种少见的金属 配合物三阶非线性光开关, 它们在性能转换、多功能性和响应速 度等方面远优于同类光开关材料. 三阶非线性光学性能测试结果 表明, 该金属配合物在光照前同时具有反饱和吸收和自散焦折射 行为. 而在光照后, 吸收行为立即消失且自散焦折射行为迅速转变 为自聚焦折射. 我们利用核磁共振技术和紫外可见吸收光谱研究 了分子结构和三阶非线性光学性能之间的关系并探究了金属离子 对三阶非线性光学行为产生的影响. 此外, 我们还通过潅浦探测技 术和密度泛函理论计算揭示了金属配合物的非线性光学性能产生 的机制. 总之, 这两种金属配合物不仅可以作为理想的三阶非线性 光开关材料, 而且也能够扩展具有可调节三阶非线性光学性能材 料的应用范围. 